\title{
Shoreline change analysis and erosion prediction using historical data of Kuala Terengganu, Malaysia
}

\begin{abstract}
At the present time, coastal changes are having a major impact in many regions of the world. Relative sea-level rise would significantly contribute to physical changes in coastal cities. Predicting the magnitude of coastal changes such as erosion and land loss is essential for a better understanding of the impacts on environment and coastal communities, as well as for management, planning and protection in coastal areas. An increase in the rate of sea-level rise and range of potential impacts, including flood and coastal erosion, will likely affect the wide East Coast of Peninsular Malaysia and would cause serious disturbance for sandy beaches, particularly in Kuala Terengganu. This study attempts to predict the future erosion in the coastal area of Kuala Terengganu, Malaysia. The shoreline erosion as a result of sea-level rise was predicted using the Bruun Rule. This is the best known model that provides a rate of shoreline erosion under sea-level rise for sandy beaches. The result of Bruun Model is analysed and presented in a Geographic Information System (GIS). Results indicate an upward trend in the future for erosion in this coastal area. The highest erosion rate is 3.20 $\mathrm{m} /$ year and the most sensitive zones are expected to be around Universiti Malaysia Terengganu (UMT) and left bank of Kuala Terengganu from 2015 to 2020. It also can provide the basic information that decision makers need when they are planning any new activity within the coastal area.
\end{abstract}

Keyword: Sandy beach erosion; Particle size analysis; Bruun model; GIS; Sand transportation 